\title{
Pola Pengelolaan Pendidikan Anak Usia Dini di Kota Gorontalo
}

\author{
Sukma Nurilawati Botutihe ${ }^{凶}$ \\ Bimbingan Konseling Universitas Negeri Gorontalo \\ DOI: $\underline{10.31004 / o b s e s i . v 4 i 2.481}$
}

\begin{abstract}
Abstrak
Pola kegiatan dalam pengelolaan sekolah non formal PAUD adalah perencanaan pendidikan, pengolahan dan analisa data pendidikan, pembiayaan pendidikan, pengembangan kurikulum, pengelolaan sumber daya manusia dan pengawasan sekolah. Tujuan penelitian ini untuk mendeskripsikan pola pengelolaan Pendidikan Anak Usia Dini di Kota Gorontalo. Penelitian ini menggunakan metode eksplanatori dan pendekatan penelitian kuantitatif bersifat deskriptif. Subjek penelitian 102 pengelola dan pendidik PAUD di Kota Gorontalo sebagai sumber informasi. Hasil penelitian menunjukkan bahwa 85\% pola pengolaan pendidikan anak usia dini di Kota Gorontalo dikatergorisasikan baik. Ditunjukkan bahwa kompetensi pengelola dan pendidik PAUD dilaksanakan secara efektif pada aspek kompetensi teknis, kompetensi kepribadian serta kompetensi sosial yang dimiliki oleh pengelola, pendidik dan pengawai tata usaha sekolah di PAUD. Adanya pola pengelolaan pendidikan anak usia dini yang berkualitas baik akan memberikan impak yang baik bagi perkembangan anak.
\end{abstract}

Kata Kunci: Pengelolaan PAUD; Pendidikan Anak Usia Dini; Anak Usia Dini

\begin{abstract}
The pattern of activities in Early childhood education non-formal school management is education planning, education data processing and analysis, education funding, curriculum development, human resource management and school supervision. The purpose of this study is to describe the management pattern of Early Childhood Education in Gorontalo City. This research uses explanatory methods and quantitative research approaches are descriptive. Research subjects 102 Early childhood education managers and educators in Gorontalo City as a source of information. The results showed that $85 \%$ of the pattern of management of early childhood education in Gorontalo City was well categorized. It was shown that the competencies of Early childhood education managers and educators were carried out effectively on aspects of technical competence, personality competencies and social competencies possessed by managers, educators and school administrators at Early childhood education. The existence of a pattern of good quality early childhood education management will give a good impact on child development.
\end{abstract}

Keywords: Management Early Childhood Education; Early childhood education; Early childhood

Copyright (c) 2020 Sukma Nurilawati Botutihe

$\triangle$ Corresponding author :

Email Address : irmabotutihe@ung.ac.id (Gorontalo, Indonesia)

Received 25 February 2020, Accepted 2 March 2020, Published 5 March 2020 


\section{PENDAHULUAN}

Pendidikan anak usia dini merupakan suatu upaya pembinaan yang memberikan stimulasi perkembangan dan pertumbuhan pada anak usia 0-6 tahun sebelum memasuki jenjang pendidikan dasar, sehingga anak memiliki kesiapan mental dan fisik dalam memasuki pendidikan lebih lanjut (Ayuni \& Setiawati, 2019; Fakhrudin, 2010; Suyadi \& Maulidya, 2013). Melalui pendidikan anak usia dini dapat membantu mengembangkan aspek perkembangan anak usia dini, baik fisik-motorik, sosial emosional, kognitif, bahasa, nilai moral agama, ataupun seni. Penting sekali pendidikan anak usia dini memberikan upaya yang optimal dalam mengembangkan pertumbuhan dan perkembangan anak. Merujuk pada Undang-Undang Republik Indonesia No. 20 Tahun 2003 Pasal 1 menyatakan bahwa Satuan pendidikan adalah kelompok layanan pendidikan yang menyelenggarakan pendidikan pada jalur formal, non formal dan informal pada setiap jenjang pendidikan, dari ketiga jalur pendidikan tersebut, pendidikan non formal didefinisikan sebagai jalur pendidikan luar pendidikan formal yang dapat dilaksanan secara terstruktur dan berjenjang. Kemudian Pasal 26 Undang-Undang Republik Indonesia (2003) tersebut pada ayat 1 bahwa pendidikan non formal diselenggarakan bagi warga masayarakat yang memerlukan layanan pendidikan yang berfungsi pengganti, penambah dan atau pelengkap pendidikan formal dalam rangka mendukung pendidikan sepanjang hayat. Artinya bahwa warga masyaarakat memiliki peranan penting dalam melaksanakan kegiatan pendidikan untuk generasi anak bangsa.

Pendidikan anak usia dini sebaiknya memiliki kualitas yang baik dalam mengembangkan pertumbuhan dan perkembangan anak. Pendidikan anak usia dini yang memiliki kualitas yang baik dapat dilihat dari segi pengolaan pendidikan anak usia dini tersebut. Jika pola pengelolaan memiliki kualitas yang baik, maka memberikan impak yang positif pada anak usia dini baik dalam jangka waktu pendek atau panjang (Ho, 2009; Province et al., 2017; Yunita et al., 2020). Sebaliknya, jika pola pengelolaan tersebut tidak baik, maka pendidikan anak usia dini tersebut memiliki kualitas yang kurang baik (Kodarni, 2016; Ridho et al., 2015).

Pengelolaan pendidikan anak usia dini merupakan manajemen yang dapat mengelolah, mengatur, dan mengerahan proses interaksi edukasi antara anak dan guru yang disusun secara teratur, terencana, tersistematis dalam mencapai tujuan lembaga pendidikan anak usia dini (Fatimah \& Rohmah, 2016; Munastiwi, 2019; Patimah \& Nurhayati, 2020). Dengan kata lain, pola pengelolaan pendidikan anak usia dini ialah model atau rancangan yang digunakan oleh suatu lembaga pendidikan dalam mengelola pendidikan anak usia dini yang bertujuan untuk meningkatkan perkembangan anak untuk memberi bekal awal sebelum anak memasuki jenjang selanjutnya. Pengelolaan dapat dilihat sebagai proses perencanaan, koordinasi, pengendalian, pemantauan, pengawasan, pengarahan dan evaluasi hasil untuk mewujudkan tujuan organisasi yang telah ditentukan sebelumnya (Çalışkan \& Özdemir, 2018; Kadir \& Adebayo, 2019). Pengelolaan atau manajemen merupakan proses di mana sekelompok orang mengerahkan tindakan yang memiliki arah tujuan bersama, yang melibatkan inisiatif dan tindakan inovatif yang membawa perubahan efektif dalam memecahkan masalah dengan menggunakan kembali sumber daya manusia dalam mencapai tujuan dan sasaran organisasi (Çalışkan \& Özdemir, 2018; Hanifah, 2018; Kadir \& Adebayo, 2019; Utami, 2018).

Ibrahim et al., (2017) berpendapat bahwa pola pengelolaan merupakan manajemen yang mengacu pada penerapan teori dan praktik manajemen bidang pendidikan atau instansi pendidikan. Proses manajemen terdiri dari lima fungsi dasar untuk mencapai tujuan organisasi pendidikan dan tujuannya. Kelima fungsi manajemen pendidikan adalah perencanaan, organisasi, mengerahkan, koordinasi, pengendalian, dan evaluasi. Kemudian pengelolaan atau manajemen memiliki tiga bidang utama wilayah studi, yaitu sumber daya manusia (siswa, guru, dan pemangku kepentingan/masyarakat sebagai pengguna layanan pendidikan), sumber belajar (alat melalui perencanaan yang digunakan sebagai media atau 
kurikulum), fasilitas dan sumber keuangan (faktor pendukung yang membuat pendidikan diselengggarakan dengan baik, tujuan pengembangan terkait, merencanakan dan mengimplementasikan program, administrasi, mengatasi masalah, pengembangan profesional.

Pada dasarnya pola pembinaan PAUD tidak lepas dari peran serta pemerintah, pengelolanya dan pendidiknya, yang memiliki sumberdaya manusia yang berkualitas. Peran pemerintah dalam Undang-undang Republik Indonesia Nomor 20 Tahun 2003 tentang Sistem Pendidikan Nasional, yakni peran pengelola dan pendidikan harus dapat mengembangkan dan menyiapkan pribadi peserta didik secara utuh dan menyeluruh. PAUD merupakan salah satu jenjang yang paling strategis serta menentukan perjalanan dan masa depan anak secara keseluruhan, serta akan menjadi fondasi bagi penyiapan anak memasuki pendidikan dasar, menengah dan pendidikan tinggi, bahkan akan mewarnai seluruh kehidupannya kelak di masyarakat. Oleh karena itu, pola pengelolaan PAUD harus menjadi prioritas perhatian yang layak dari berbagai pihak, baik keluarga, pemerintah dan masyarakat.

Dalam hal pengembangan kapasitas yang dibutuhkan untuk pengelolaan pendidikan tidak hanya berfokus pada pembangunan di sekolah tetapi harus memperhatikan pengembangan pengelolaan pendidikan yang efektif (Depdiknas, 2004)“....Fungsi-fungsi pengelolaan pendidikan yang dibutuhkan telah diidentifikasi: perencanaan pendidikan, pengolahan dan analisa data pendidikan, pembiayaan pendidikan, pengembangan kurikulum, pengelolaan aset, pengelolaan sumber daya manusia dan pengawasan sekolah". Artinya bahwa untuk mengetahui apakah pengelolaan di sekolah efektif atau tidak dapat ditelusuri melalui penilaian tentang perencanaan pendidikan, pengolahan dan analisa data pendidikan, pembiayaan pendidikan, pengembangan kurikulum, pengelolaan aset, pengelolaan sumber daya manusia dan pengawasan sekolah, apakah tercapai atau tidak.

Pengelolaan pendidian anak usia dini yang dirancang dengan baik dan diorganisir secara interaktif dan menginspirasi, akan membuat pembelajaran lebih menyenangkan, menantang, dan mendorong kreativitas anak (Qodriyati \& Raharjo, 2018). Namun pada kenyataanya terdapat beberapa masalah dalam pola pengelolaan pendidikan anak usia dini. Yunita et al., (2020) pengelolaan pendidikan anak usia dini memiliki permasalahan bahwa belum ratanya jangkauan layanan pendidikan anak usia dini dan kualitas pengelolaannya. Selain itu, hasil wawancara yang dilakukan dengan kepala Bidang PAUD dan PNF Dinas Pendidikan dan Kebudayaan Kabupaten Serang pada tahun 2018 bahwa tidak adanya pelatihan-pelatihan dalam pengelolaan pendidikan anak usia dini. Permasalahan mendasar dalam bidang pendidikan ialah perbaikan sumber daya manusia seperti pendidik yang belum optimal dalam mengembangkan potensi yang dimilikinya, sehingga mempengaruhi pola pengelolaan pada pendidikan anak usia dini (Gilmour et al., 2018; Macías, 2018; Maiza \& Nurhafizah, 2019; Roza et al., 2020).

Sugita \& Ansori (2018) permasalahan terjadi tidak hanya kualifikasi akademik pendidik atau tenaga pendidik PAUD, melainkan kurangnya pemahaman pengelola mengenai manajemen yang baik dan sesuai aturan dalam sebuah lembaga PAUD. Selain tu, permasalahan yang terjadi adalah banyak lembaga PAUD yang tutup diakibatkan oleh minimnya dana yang dimiliki oleh lembaga tersebut, kurangnya ilmu pengetahuan guru dalam mengelola PAUD sehingga tenaga pendidik dan kependidikan lembaga tersebut tidak dapat bekerja secara profesional (Suharti, 2018).

Berdasarkan observasi awal penelitian pola pengelolaan sekolah PAUD dapat dilihat pada awal bentuk pengelolaan sekolah PAUD di kota gorontalo, diantaranya untuk sekolah PAUD mentari berawal dari adanya bentuk perhatian pemerintah kelurahan heledulaa selatan dalam mengelola adanya PAUD dan untuk lainnya awal berdirinya dari swasata/yayasan sukma Nusa bangsa, sehingga asumsinya bahwa keberadaan PAUD untuk meningkatkan kualitas generasi emas bangsa yang berkualitas, dan akses sekolah yang dapat mengakomodir anak-anak sekitar yang kurang mampu dari segi ekonomi, serta 
menyediakan fasilitas bermain dan pendidikan untuk masyarakat yang akses fasilitas di rumahnya kurang memadai, sehingga dalam penelitian ini penulis memaparkan secara rinci bagaimana Pola Pengelolaan Pendidikan Anak Usia Dini Di Kota Gorontalo. Selain itu, tujuan penelitian ini adalah untuk mendesripsikan pola pengelolaan pendidikan anak usia dini yang ada di kota Gorontalo.

\section{METODOLOGI}

Jenis penelitian ini adalah eksplanatori dan pendekatan penelitiannya kuantitatif yang bersifat secara deskriptif yang berkaitan dengan pola pengelolaan PAUD Di Kota Gorontalo. Berikut ini tahap penelitian yang dilakukan.

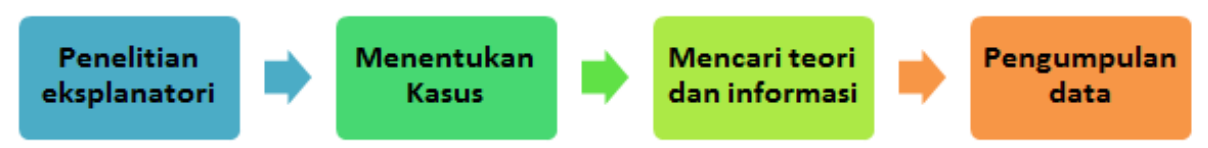

Gambar 1. Tahapan Penelitian Eksplanatori (Raco, 2010)

Subjek penelitian adalah sejumlah 102 pengelola dan pendidik PAUD yang dijadikan sumber informasi, khususnya informasi tentang pola pengelolaan PAUD Di Kota Gorontalo, dengan indikator: 1) Perencanaan pendidikan, 2) Pengolahan dan analisa data pendidikan, 3) Pembiayaan pendidikan, 4) pengembangan kurikulum, 5) pengelolaan aset, 6) pengelolaan sumber daya manusia, dan 7) pengawasan sekolah. Teknik analisis data dari penelitian ini menggunakan analisis deskriptif dalam bentuk tabel frekuensi dengan formula sebagai berikut: Menentukan frekuensi capaian responden untuk setiap butir angket dengan rumus sebagai berikut :

$$
\mathrm{P}=\frac{f}{N} \times 100 \%
$$

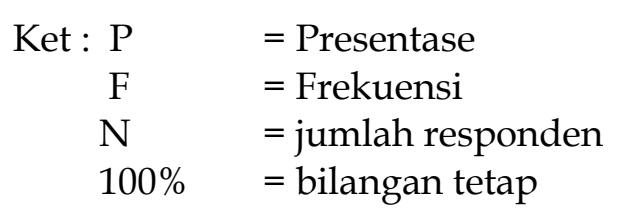

Menghitung persentase dalam skor digunakan dalam rumus sebagai berikut :

$$
\operatorname{Pr}=\frac{S A}{S I} \times 100 \%
$$

Ket: $\operatorname{Pr}=$ persentase hasil penelitian

SA = skor actual, yaitu merupakan total skor yang diperoleh seluruh responden

SI = skor ideal, yaitu jumlah skor maksimum yang dicapai

$100 \%=$ bilangan tetap

Tabel 1. Kualifikasi Kriteria

\begin{tabular}{ccc}
\hline No & Rentang Skor $\%$ & Kriteri \\
\hline 1 & $91-100$ & Sangat Baik \\
2 & $76-90$ & Baik \\
3 & $51-75$ & Cukup Baik \\
4 & $\leq 50$ & Tidak Baik. \\
\hline
\end{tabular}

(Sugiyono, 2013) 


\section{HASIL DAN PEMBAHASAN}

Pola Pengelolaan Pendidikan Anak Usia Dini (PAUD) Di Kota Gorontalo, dapat dilihat melalui struktur organisasi lembaga PAUD terpadu. Berikut ini gambar dari struktur organisasi lembaga PAUD terpadu.

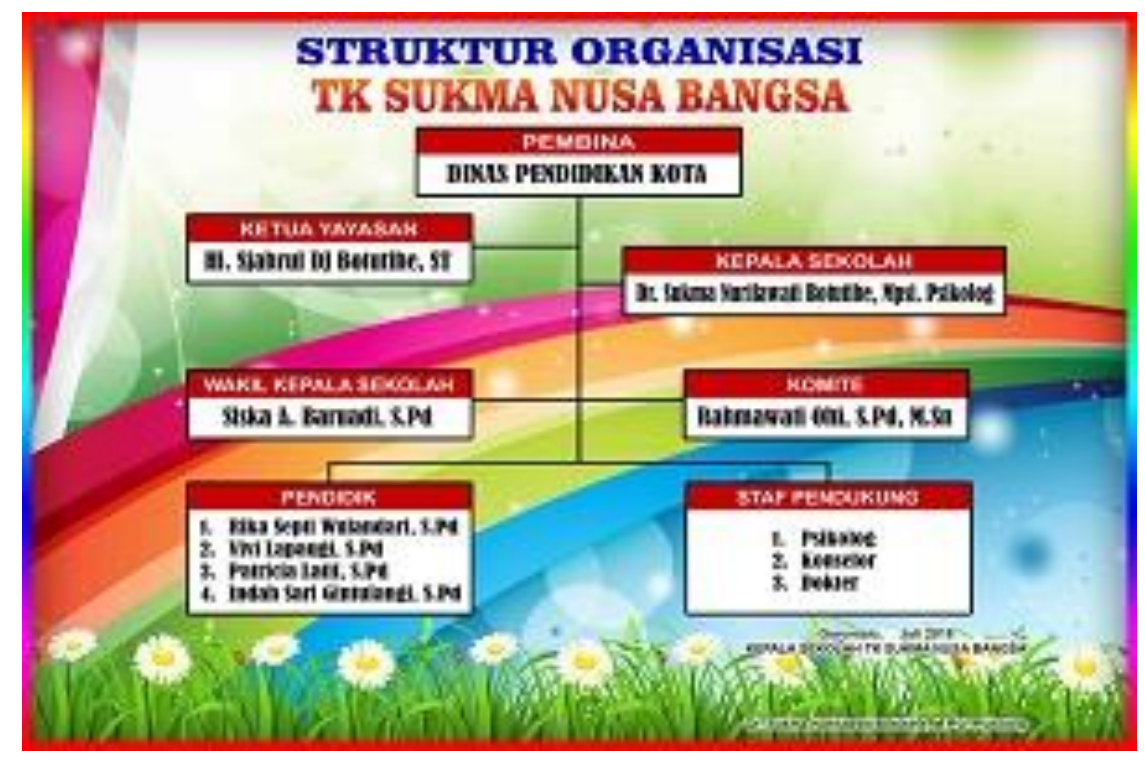

Gambar 2. Struktur Organisas Lembaga PAUD Terpadu

Lembaga, sekolah atau satuan PAUD sebagai salah satu bentu layanan pendidikan anak usia dini pada jalur pendidikan non formal yang mengutamakan kegiatan bermain sambil belajar. Penyelenggaraan satuan Pendidikan Anak Usia Dini (PAUD) dapat dilaksanakan oleh lembaga baik swasta, pemerintah, organisasi masyarakat maupun perseorangan yang memiliki kepedulian terhadap Pendidikan Anak Usia Dini (PAUD), baik lembaga maupun perorangan harus memperoleh izin dari Dinas Pendidikan Kota/Kabupaten atau instansi lain yang di tunjuk oleh pemerintah daerah setempat. Adapun syarat-syarat yang harus dipenuhi dalam pengajuan izin penyelenggaraan Pendidikan Anak Usia Dini (PAUD), yaitu; 1) Surat permohonan Kepala Dinas Pendidikan Kabupaten, Cq. Kabid PLSPO yang di ketahui oleh lurah, camat dan dan pemilik PLS Kecamatan 2) Akte Notaris pendirian yayasan. 3) Bentuk dan nama lembaga 4) Visi dan misi nama lembaga 5) Program kegiatan mengajar. 6) Sarana dan prasarana 7) Data dan keterangan yang berisi; a) Data pengelola, pendidik, pengasuh (fotocopy SK pengangkatan, Ijazah terakhir, jumlah jam mengajar). b) Data peserta didik. c) Denah lokasi d) Surat Keterangan Kepemilikan Bangunan e) Surat ijin lingkungan diketahui, kadus/kepala lingkungan/lurah. f) Struktur Organisasi. Masa berlaku izin penyelenggara PAUD, adalah 3 tahun sejak tanggal diterbitkan SK atau disesuaikan dengan kebijakan yang telah ditetapkan oleh Dinas terkait, karena masing-masing dinas Kota/Kabupaten mempunyai kebijakan sendiri (otonomi daerah).

Sesuai hasil lapangan data penelitian, bahwa Pengelolaan Lembaga PAUD agar dapat berjalan secara efektif dan efisien diperlukan adanya penataan, pengaturan, pengelolaan dan kegiatan lain yang sejenis. Langkah-langkah tersebut harus dikonsepkan secara sistematis, sesuai dengan fungsi manajemen, dengan demikian hal ini relevan dengan pendapat dari Mustar (2014) bahwa Pengelolaan dapat diartikan sebagai manajemen, dalam hal ini pengelolaan lembaga yang menitik beratkan pada empat komponen yaitu Pengelolaan tenaga kerja, pendidik dan tenaga pendidik, peserta didik, sarana dan prasarana, pengelolaan keuangan.Hasil Pola pengolahan angket pengelolaan PAUD yang efektif adalah bentuk pencapaian tujuan sekolah sehingga memberikan manfaat dan kegunaan bagi warga sekolah dan masyarakat, terutama kegiatan-kegiatan menyangkut; 1) 
perencanaan pendidikan. 2) pembinaan kepribadian, sikap, perilaku, 3) pengolahan dan analisa data pendidikan. 4) pembiayaan pendidikan 5) pengembangan kurikulum. 6) pengelolaan aset. 7) pengelolaan sumber daya manusia dan 8) pengawasan sekolah

Hasil penelitian indikator Kompetensi teknis perencanaan pendidikan untuk pengelola dan pendidik PAUD di Kota Gorontalo, mencapai hasil 79,3\% dengan kriteria baik, bahwa Kompetensi teknis perencanaan adalah keterampilan atau skill yang dimiliki seseorang pengelola dan pendidik dalam menunjukan seberapa besar pengetahuan dan penguasaan terhadap suatu pekerjaan. Secara teknis perencanaan, keterampilan adalah hal yang mendasar untuk melakukan suatu pekerjaan yang akan dilaksanakan. Kompetensi teknis perencenaan yaitu kompetensi mengenai bidang yang menjadi tugas pokok organisasi. Kompetensi teknis perencanaan mendorong pengelola, pendidik dan pegawai PAUD untuk merencanakan program akademik, skill keterampilan mereka dalam melaksanakan tugas proses pembelajarannya. Kompetensi teknis mengenai perencanaan, dalam melaksanakan adminsitrasi pembelajaran, persuratan dan pengarsipan yakni tenaga administrasi memiliki kemampuan untuk menerapkan pengelolaan admnistrasi/akademik, untuk profesionalisasi tenaga pengelola, pendidik dan administrasi sekolah harus memahami peraturan akademik PAUD. Selanjutnya, indikator hasil penelitian Kompetensi pembinaan PAUD melalui kepribadian, sikap, perilaku pengelola dan pendidik PAUD di Kota Gorontalo, pada angka 78,4\%, hal ini dapat ditunjukkan dengan ranah afektif pengelola dan pendidik agar peserta didik dapat menerima pelajaran dengan baik dan enjoy, sesuai dengan konsep belajar sambil bermain, agar anak-anak dapat bersikap lebih baik kepada pendidik, sebab sikap anak PAUD itu akan mencontoh.

Kompetensi pengolahan dan teknis analisa data pendidikan akademik; kompetensi social, agama dan psikologi PAUD untuk proses pembelajaran dan administrasi pengelola dan pendidik PAUD di Kota Gorontalo, hasilnya adalah 87,3\%, ini menunjukkan bahwa kompetensi ini penting untuk lebih di tingkatkan melalui proses pembelajaran dan sosialiasi anak didik melalui pembinaan dan arahan pengelolaan dan pendidik. Kemudian hasil dari analisis pembiayaan pendidikan oleh pengelola dan pendidik untuk pola pembinaan akademik dan ekstrakurikuler peserta didik adalah 78,2\% untuk memaksimalkan pengelolaan ini maka perlu ditingkatkan pengelolaan tenaga pendidik dan tenaga kependidikan, melalui kedisiplinan pendidik, tanggungjawab pengelola dan tertib admnitrasi untuk pegawai tata usaha.

Selanjutnya hasil penelitan dari pembinaan keilmuan pengembangan kurikulum PAUD untuk pengelola dan pendidik, dengan nilai $78,1 \%$ dapat di maksimalkan dengan peningkatan keilmuan melalui; pelatihan, seminar dan kelanjutan jenjang pendidikan, minimal pendidikan S1 PAUD untuk pendidik paud, agar sumberdaya manusia berkualitas dengan keilmuannya. Pada hasil peneltian pola pengelolaan asset didapatan nilai yaitu $79,3 \%$ dengan sisa 27,7\% dapat ditingkatkan melalui pengelolaan bangunan, jadi hak milik, sarana dan prasarana yang dapat menunjang proses pembelajaran. Hasil penelitian dari pola pengelolaan Sumber daya manusia dengan nilai $77,1 \%$, hal ini di tunjukkan oleh adanya kualitas kelimuan yang dapat menunjang peningkatan output dan outcomes lulusan, sehingga pengelola, pendidik dan tenaga admnistrasi dapat selalu meningkatkan kualitas keilmuan dan tupoksinya. Hasil Pola Pengawasan Sekolah mendapatkan nilai 88,4\%, dengan sisa 16, 96\% dapat di optimalkan, melalui evaluasi dan pengawasan oleh pemerintah terkait, yakni diantaranya melalui peningkatan nilai akreditasi. Selanjutnya dijelaskan dalam tabel dibawah ini: 
Tabel 2. Rekapitulasi variabel Pola Pengelolaan Pendidikan Anak Usia Dini Di Kota Gorontalo.

\begin{tabular}{|c|c|c|c|c|}
\hline No & Indikator & $\begin{array}{l}\text { Rata-Rata } \\
\text { Skor } \\
\text { Capaian }\end{array}$ & $\begin{array}{l}\text { Rata-Rata } \\
\text { Persentase }\end{array}$ & Kategori \\
\hline 1. & $\begin{array}{l}\text { Kompetensi teknis perencanaan pendidikan untuk } \\
\text { pengelola dan pendidik PAUD di Kota Gorontalo }\end{array}$ & 82.5 & $79.3 \%$ & Baik \\
\hline 2. & $\begin{array}{l}\text { Kompetensi pembinaan PAUD melalui kepribadian, sikap, } \\
\text { perilaku pengelola dan pendidik PAUD di Kota Gorontalo }\end{array}$ & 81.9 & $78.4 \%$ & Baik \\
\hline 3. & $\begin{array}{l}\text { Kompetensi pengolahan dan teknis analisa data pendidikan } \\
\text { akademik; kompetensi social, agama dan psikologi PAUD } \\
\text { untuk proses pembelajaran dan administrasi pengelola dan } \\
\text { pendidik PAUD di Kota Gorontalo }\end{array}$ & 90.8 & $87.3 \%$ & Baik \\
\hline 4 & $\begin{array}{l}\text { Analisis pembiayaan pendidikan oleh pengelola dan } \\
\text { pendidik untuk pola pembinaan akademik dan } \\
\text { ekstrakurikuler peserta didik }\end{array}$ & 81.2 & $78.2 \%$ & Baik \\
\hline 5 & $\begin{array}{l}\text { Pembinaan keilmuan pengembangan kurikulum PAUD } \\
\text { untuk pengelola dan pendidik }\end{array}$ & 81,3 & $78,1 \%$ & Baik \\
\hline 6 & Pola Pengelolaan Aset & 82.5 & $79.3 \%$ & Baik \\
\hline 7 & Pola Pengelolaan Sumberdaya manusia & 80.01 & $77.1 \%$ & Baik \\
\hline 8 & Pola Pengawasan Sekolah & 91.9 & $88.4 \%$ & Baik \\
\hline & Jumlah & 88.4 & $85 \%$ & Baik \\
\hline
\end{tabular}

Sumber : Data diolah, 2019

Rekapitulasi hasil persentase mengenai Pola Pengelolaan Pendidikan Anak Usia Dini Di Kota Gorontalo. menunjukan bahwa 85\% berada pada kategori Baik. Kesimpulannya bahwa Pola Pengelolaan Pendidikan Anak Usia Dini Di Kota Gorontalo telah dilakukan dengan efektif. Sesuai penelitian ini menunjukan bahwa kompetansi pengelola dan pendidik serta pegawai tata usaha dalam pengelolaan PAUD di Kota Gorontalo efektif pada aspek kompetensi teknis, kompetensi kepribadian serta kompetensi sosial yang dimiliki oleh pengelola, pendidik dan pegawai tata usaha sekolah PAUD.

Pengelolaan pada pendidikan anak usia dini sangat penting dilakukan, karena pengelolan mempengaruhi kualitas instansi tersebut. Jika pola pengelolaan memiliki kualitas yang baik, maka memberikan impak yang positif pada anak usia dini baik dalam jangka waktu pendek atau panjang (Ho, 2009; Province et al., 2017; Yunita et al., 2020). Sebaliknya, jika pola pengelolaan tersebut tidak baik, maka pendidikan anak usia dini tersebut memiliki kualitas yang kurang baik (Kodarni, 2016; Ridho et al., 2015). Hasil penelitian menunjukkan bahwa rata-rata skor pencapaian 88,4 yang ditunjukkan dengan rata-rata presentase $85 \%$ yang dikategoriasasikan baik pada pola pengelolaan PAUD di Kota Gorontalo baik dari indikator kompetensi teknis, kompetensi pembinaan, Kompetensi pengolahan dan teknis analisa data pendidikan akademik, Analisis pembiayaan pendidikan, Pembinaan keilmuan pengembangan kurikulum PAUD untuk pengelola dan pendidik, Pengelolaan Aset, Pengelolaan sumberdaya Manusia, dan Pengawasan Sekolah. Dengan adanya pengelolaan PAUD yang tepat akan meningkatkan perkembangan anak dalam memberi bekal awal sebelum anak memasuki jenjang pendidikan selanjutnya.

\section{SIMPULAN}

Berdasarkan hasil persentase mengenai Pola Pengelolaan Pendidikan Anak Usia Dini Di Kota Gorontalo. menunjukan bahwa 85\% berada pada kategori Baik. Kesimpulannya bahwa Pola Pengelolaan Pendidikan Anak Usia Dini Di Kota Gorontalo telah dilakukan dengan efektif. Sesuai penelitian ini menunjukan bahwa kompetansi pengelola dan pendidik serta pegawai tata usaha dalam pengelolaan PAUD di Kota Gorontalo efektif pada aspek kompetensi teknis, kompetensi kepribadian serta kompetensi sosial yang dimiliki oleh pengelola, pendidik dan pegawai tata usaha sekolah PAUD. 


\section{UCAPAN TERIMAKASIH}

Terima kasih peneliti ucapkan kepada pihak yang terkait yang telah membantu dalam menyelesaikan penelitian ini, terutama kepada lembaga Pendidikan Anak Usia Dini di Kota Gorontalo.

\section{DAFTAR PUSTAKA}

Ayuni, D., \& Setiawati, F. A. (2019). “Kebun Buah" Learning Media for Early Childhood Counting Ability Despa. Jurnal Obsesi: Jurnal Pendidikan Anak Usia Dini, 3(1), 1-9. https:// doi.org/10.31004/obsesi.v3i1.128

Çalışkan, A., \& Özdemir, A. (2018). Meeting Management Skills of District Directors of National Education According to Perceptions of School Managers. Journal of Education and Training Studies, 6(11), 113-127. https://doi.org/10.11114/jets.v6i11.3200

Depdiknas. (2004). Standar Kompetensi Guru. Depdiknas.

Fakhrudin, A. . (2010). Sukses Menjadi Guru TK/PAUD. Bening.

Fatimah, D. F., \& Rohmah, N. (2016). Pola Pengelolaan Pendidikan Anak Usia Dini di PAUD Ceria Gondangsari Jawa Tengah. MANAGERIA: Jurnal Manajemen Pendidikan Islam, 1(November), 247-273. https:// doi.org/ doi.org/10.14421/manageria.2016.12-05

Gilmour, A. F., Majeika, C. E., Sheaffer, A. W., \& Wehby, J. H. (2018). The Coverage of Classroom Management in Teacher Evaluation Rubrics. Teacher Education and Special Education. https://doi.org/10.1177/0888406418781918

Hanifah, H. (2018). Penerapan Manajemen Program Pembelajaran Bagi Guru Paud Dalam Meningkatkan Kinerja Pendidik. Comm-Edu (Community Education Journal), 1(3), 24. https:// doi.org/10.22460/comm-edu.v1i3.1102

Ho, C. D. (2009). Human resource management in Hong Kong preschools: the impact of falling rolls on staffing. International Journal of Educational Management, 23(3), 217-226. https:// doi.org/10.1108/09513540910941720

Ibrahim, I. A. A., Ali, I. A., \& Abdalla, M. S. (2017). Educational Management, Educational Administration and Educational Leadership: Definitions and General concepts. SAS $\begin{array}{lll}\text { Journal of } & \text { Medicine 326-329. }\end{array}$ https:// doi.org/10.21276/sasjm.2017.3.12.2

Kadir, N. J., \& Adebayo, T. A. (2019). Digitization In Education System and Management of Early Childhood Care Education in Nigeria. Southeast Asia Early Childhood Journal, $8(2), 28-42$.

Kodarni. (2016). Kualitas Manajemen Kurikulum PAUD IT Cerliana Kota Pekanbaru. UPT Perpustakaan UNJ.

Macías, D. F. (2018). Classroom Management in Foreign Language Education: An Exploratory Review. Universidad Nacional de Colombia, Facultad de Ciencias Humanas, Departamento de Lenguas Extranjeras, 20(1), 153-166.

Maiza, Z., \& Nurhafizah, N. (2019). Pengembangan Keprofesian Berkelanjutan dalam Meningkatkan Profesionalisme Guru Pendidikan Anak Usia Dini. Jurnal Obsesi: Jurnal Pendidikan Anak Usia Dini, 3(2), 356. https:/ / doi.org/10.31004/obsesi.v3i2.196

Munastiwi, E. (2019). Manajemen Ekstrakurikuler Pendidikan Anak Usia Dini (PAUD). MANAGERIA: Jurnal Manajemen Pendidikan Islam, 3(2), 369-380. https:// doi.org/10.14421/manageria.2018.32-09

Mustar, M. (2014). Manajemen Pendidikan. PT Raja Grafndo.

Patimah, R. S., \& Nurhayati, S. (2020). Manajemen Lembaga Taman Kanak-kanak Berprestasi dalam Rangka Mencetak Anak Usia Dini yang Unggul dan Berkarakter. Comm-Edu (Community Education Journal), 6-17. https:// doi.org/dx.doi.org/10.22460/comm-edu.v3i1.3296

Province, S., Sawaddemongkol, P., Boonphak, K., \& Pimsarn, N. (2017). Development of Efficiency Management System for Private Kindergarten Schools in Samutprakan Province, Thailand. Creative Education, 8, 1099-1110. 
DOI: 10.31004/obsesi.v4i2.481

https://doi.org/10.4236/ce.2017.87079

Qodriyati, T. U., \& Raharjo, T. J. (2018). Learning Management of Early Childhood Education at Mentari Kids. Journal of Nonformal Education, 4(1), 57-68. https://doi.org/dx.doi.org/10.24914/pnf.v4i1.13574

Raco. (2010). Metode Penelitian Kualitatif Jenis, Karakteristik dan Keunggulannya. Jakarta: PT Gramedia Widiasarana Indonesia. https:/ / books.google.co.id/books?id=dSpAlXuGUCUC\&pg=PA50\&dq=bagan + pene litian+eksplanatori\&hl=id\&sa=X\&ved=0ahUKEwjy0YXIh4LoAhXjjeYKHTjMBzMQ6 $\mathrm{AEIMDAB} \# \mathrm{v}=$ onepage $\& \mathrm{q} \& \mathrm{f}=$ false

Republik Indonesia. (2003). Undang-Undang Republik Indonesia Nomor 20 Tahun 2003 Tentang Sistem Pendidikan Nasional. In Lembaran Negara RI Tahun 2003, No. 20. Seketariat Negara.

Ridho, R., Markhamah, \& Darsinah. (2015). Pengelolaan pembelajaran pendidikan anak usia dini (PAUD) di kb "cerdas" kecamatan sukorejo kabupaten kendal. Penelitian HUmanora, 16(3), 59-69.

Roza, D., Nurhafzah, \& Yaswinda. (2020). Urgensi Profesionalisme Guru Pendidikan Anak Usia Dini dalam Penyelenggaraan Perlindungan Anak. Jurnal Obsesi: Jurnal Pendidikan Anak Usia Dini, 4(1), 267-273. https:/ / doi.org/10.31004/obsesi.v4i1.325

Sugita \& Ansori. (2018). Jurnal comm-edu. Jurnal Comm-Edu, 1(20), 127-137. https://doi.org/dx.doi.org/10.22460/comm-edu.v1i2.639

Sugiyono. (2013). Metode Penelitian Pendidikan Pendekatan Kuantitatif, Kualitatif, dan RED. Alfabeta.

Suharti, S. (2018). Manajemen Pendidikan Anak Usia Dini (PAUD) dalam Rangka Meningkatkan Mutu Pembelajaran (Studi pada PAUD Negeri Pembina Curup dan PAUD Pertiwi Kabupaten Rejang Lebong). Tadbir : Jurnal Studi Manajemen Pendidikan, 2(1), 51. https://doi.org/10.29240/jsmp.v2i1.397

Suyadi, \& Maulidya, U. (2013). Konsep Dasar PAUD. PT Remaja Rosdakarya.

Utami, E. (2018). Management Of Kindergarten (TK) Parenting Program in Mujahidin 2 on East Pontianak District. Journal of Education, Teaching, and Learning, 3(2), 273-281.

Yunita, W., Utami, D., Jamaris, M., \& Meilanie, S. M. (2020). Evaluasi Program Pengelolaan Lembaga PAUD di Kabupaten Serang Abstrak. Jurnal Obsesi : Jurnal Pendidikan Anak Usia Dini, 4(1), 67-76. https:/ / doi.org/10.31004/obsesi.v4i1.259 